Jersey. After working as a postdoc and staff scientist at the Molecular Foundry, he became director of the Molecular Foundry in 2013. Neaton is the recipient of a US Department of Energy Presidential Early Career Award for Scientists and Engineers, and is a Fellow of the American Physical Society.

Iris Visoly-Fisher is a senior lecturer with the Department of Solar Energy and Environmental Physics at the Swiss Institute for Dryland Environmental and Energy Research and the Blaustein Institute for Desert Research at Ben-Gurion Univer- sity of the Negev, Israel. She received her $\mathrm{BSc}$ and MSc degrees in materials engineering and a BA degree in physics from

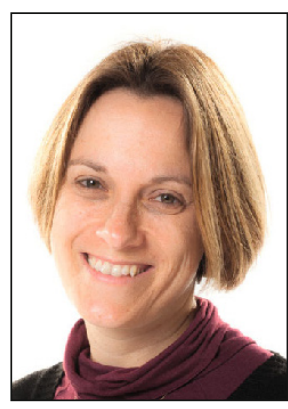

the TechnionIsrael Institute of Technology. She completed her $\mathrm{PhD}$ degree in materials and interfaces at the Weizmann Institute of Science in 2004, studying single grain boundaries in polycrystalline
CdTe solar cells. She was a postdoctoral fellow at Arizona State University, where she studied electrochemical potentialdependent current transport in single biomolecules. She joined Ben-Gurion University of the Negev as an assistant professor in 2008. Her current research interests include materials for solar-energy conversion and storage, optoelectronics, and surface science. She is an executive committee member of the Israel Vacuum Society, an editorial board member of the journal Scientific Reports, and a MRS member since 2000

\title{
PREVIEW: XXVII International Materials Research Congress 2018
}

August 19-24, Cancún, Mexico • www.mrs.org/imrc-2018

$\mathrm{T}_{\mathrm{s}}^{\mathrm{h}}$ Materials Research Society (MRS) and the Sociedad Mexicana de Materiales (SMM) are excited to be working together to host the International Materials Research Congress (IMRC) held annually in Cancun, Mexico. The 27th IMRC will be held August 19-24, 2018. The Meeting chairs are Hans M. Christen, Oak Ridge National Laboratory (USA); Coray M. Colina, University of Florida (USA); Ciro Falcony, Centro de Investigación y de Estudios del Instituto Politécnico Nacional (Mexico); and Cecilia Noguez, Universidad Nacional Autónoma de México (Mexico).

The Congress will feature 38 symposia covering nanomaterials and 2D materials; hybrid materials, bioinspired materials, and soft matter; materials for energy conversion, storage, and harvesting; development of new characterization, modeling, data analytics, and design methods; structural materials and metallurgy; and a general cluster on a variety of topics.

Everyone registered for the meeting may take part in the fourth NANOMXCN: Mexico-China Workshop on "Nanomaterials, Science, Technology: Renewable Energy and Environment Remediation." The project aims to promote collaboration between Mexico and China, including the Hong Kong Special Administrative Region (SAR), with the support of colleagues worldwide. The workshop will focus on the use of nanostructured materials to address issues in modern day society in the fields of renewable energy and environmental remediation, and will include short sessions to exchange ideas for the design of specific actions to prepare dynamic collaborations. The meeting will also include an "Advanced Defense Materials" workshop, which will focus on the design, synthesis, integration, and application of novel materials/processes to address defense application needs.

Several tutorials will be offered to complement the symposium sessions, including Computational DFT Methods for Catalytic Materials; Design of Advanced Steels and Advanced Coating for Steels; Electron Crystallography in TEM: Orientation Imaging to Strain and Metals to Archaeology at $\mathrm{nm}$ Scale; Hybrid Perovskite Solar Cells: Fundamentals to Cell Fabrication and Scale-Up; Mentoring Young Scientists: Developing Survival Skills; Probing Nanomaterials in Space or Time with High Spatial and Energy Resolution; and Texture and Microstructure Analysis Using Electron Backscatter Diffraction.
Plenary speakers at this year's event are Susan Trolier-McKinstry, The Pennsylvania State University, USA; Yuichi Ikuhara, The University of Tokyo, Japan; Amanda S. Barnard, CSIRO, Australia; Ben L. Feringa, University of Groningen, The Netherlands; and Galo Soler Illia, Universidad Nacional de San Martín, Argentina. Leonardo Beltrán Rodriguez, Deputy Secretary for Planning and Energy Transition, Mexico, will present the Science, Technology, and Society Lecture.

To promote postgraduate degrees in materials science and engineering and related areas, the Mexican Society of Materials will organize an exhibition with the IMRC. There will also be an exhibit of instruments, products, and services in the field of materials science and related topics, with participation by worldrenowned companies.

This annual meeting provides an exciting multidisciplinary stage to present new directions in materials research and technology, as well as opportunities to exchange ideas with some of the foremost experts in the field. IMRC has become a leading conference with approximately 1700 attendees from more than 50 countries.

For more information, visit www.mrs. org/imrc-2018. 